\title{
Discussion on the main points of construction quality control in civil engineering
}

\author{
Xiangming Zhou
}

Shenzhen Jingchengye Civil Engineering Co., Ltd. Shenzhen City, Guangdong Province, China; XMZhou@163.com

Abstract: With the improvement of comprehensive development level, civil engineering is perceived a promoted position in the development of the whole market economy in China. Civil engineering is an important link for building construction. Good civil engineering construction management ensures the overall engineering quality control level. Through the reasonable analysis of construction standards, construction contents and construction steps of civil engineering, the actual construction control and management methods of civil engineering are defined, the effective control scheme of civil engineering quality is analyzed, and reasonable suggestions for solving problems are put forward, so as to realize effective control and management of civil engineering construction quality in China. This paper makes an analysis of the actual construction control and fully studies the measures and schemes of the actual construction quality control to improve the management efficiency of the construction quality control of civil engineering.

Keywords: Civil engineering; construction quality; control analysis

Received: November 18, 2019 Accepted: December 21, 2019 Published: December 25, 2019

\section{Introduction}

In the process of civil engineering construction, quality level of the overall construction project can be effectively improved through reasonable quality control. According to the actual content and steps, the management of partial items can be carried out, the actual civil engineering quality planning content can be clearly defined, the relevant civil engineering quality level can be reasonably and effectively analyzed, the control standard of civil engineering construction quality can be improved, and the technical research level of civil engineering construction quality can be improved.
During civil engineering construction process, it is often necessary to make a detailed analysis of construction management, construction standards, construction contents, construction material costs, construction personnel control, construction supervision and management, etc., to clarify the key points and points of construction, to analyze the detailed rules of construction quality control management, to accurately analyze the standards of construction management quality control, to ensure that civil engineering construction meets the needs of overall development, and to improve the analysis and development of civil engineering construction quality.

\footnotetext{
Copyright (C) 2019 Xiangming Zhou

doi: $10.18282 /$ ice.v2i1.304

This is an open-access article distributed under the terms of the Creative Commons Attribution Non-Commercial License

(http://creativecommons.org/licenses/by-nc/4.0/), which permits non-commercial use, distribution, and reproduction in any medium, provided the original work is properly cited.
} 


\section{The content of basic effective control of civil engineering construction quality}

\subsection{Improve the overall level of construction management}

It is necessary to analyze according to the quality level of the whole project, define the control standard and management mechanism of the overall construction quality, and define the main content of actual cost control in the construction management of civil engineering, Analyze the improper management of civil engineering construction quality according to specific requirements. The deficiencies in the quality of engineering management and various unreasonable phenomena in engineering accidents are analyzed, the engineering quality management level is gradually improved, the integrity of the overall system of construction quality is ensured, the arrangement of materials used in the actual construction process is clarified, and the earned amount is divided into the engineering content and engineering responsibilities. Analyze the work arrangement of construction personnel on site, analyze the construction contents and links of civil engineering, specify the labeling of actual construction processing materials, analyze the management level of equipment maintenance inspection and supervision, and ensure the rationality of management efficiency of engineering construction quality and safety.

\subsection{Deepening the system construction of civil engineering construction management}

According to the construction process of civil engineering, accurate analysis of the construction quality management objectives, accurate analysis of the far-reaching significance of construction quality control, to help standardize the management of civil engineering construction system, improve the enterprise's own quality control and mechanism management. In the process of enterprise construction, it is necessary to establish an effective management system standard according to the actual needs, and comprehensively consider the overall enterprise's construction environment, construction personnel, technical standards, capital and equipment construction conditions, etc. According to the requirements, establish a quality control and management mechanism in line with the development of the enterprise itself, ensure the full adaptive value of each link in the overall construction of civil engineering, continuously improve the overall work value and work efficiency, and ensure the level of work quality. In the construction of civil engineering, it is necessary to avoid as much as possible all kinds of unreasonable loophole problems caused by imperfect construction management system, ignoring all kinds of hidden trouble problems that may occur, directly affecting the construction quality level and causing all kinds of loss problems. In order to ensure the rationality of each construction link in civil engineering and improve the overall work efficiency, the Smithsonian Project needs to formulate scientific construction management scope according to the requirements to ensure the controllability and safety rationality of the overall quality of civil engineering.

\subsection{Improve the effective supervision and management level of construction quality}

In civil engineering construction management, it is necessary to define all kinds of construction management links and re-analyze all kinds of hidden dangers that may occur, to make reasonable analysis of defects in all links of quality problems, to strengthen the overall supervision and management efficiency, and to analyze the prominent situation of all kinds of links. Through the supervision and management of the quality and content of civil engineering construction management, the safe operation effect of civil engineering management is made clear, and the division of any responsibilities in civil engineering construction management is made clear, so as to ensure the smooth construction and safety control. In the existing construction, civil engineering construction units should often carry out safety management on the overall construction, analyze the hidden dangers that may exist in different links, identify all kinds of problems existing therein, and improve the lack of supervision and management. 


\section{Civil engineering construction quality control measures management}

\subsection{To develop scientific and reasonable construction quality management control mechanism}

It is necessary to analyze and implement the construction quality problems of civil engineering and formulate a complete, systematic and efficient feasible construction scheme in the construction management of civil engineering. Moreover, it is necessary to carry out construction according to the construction quality standards, formulate a scientific and reasonable construction management system, define the actual construction quality control methods, carry out quality plan analysis on different links, and improve the management of the construction quality mechanism in terms of completeness, systematicness, operability and supervision in the process of civil engineering construction.

\subsection{Control countermeasures to improve construction management}

\subsubsection{Strengthen personnel planning management and construction}

Normative management of personnel is the key link to improve the quality management level of civil engineering construction. According to the requirements, the actual personnel control standards shall be defined, and the actual work management scope and control standards of constructors, managers, technical operators, quality monitoring personnel, etc. shall be determined, so as to gradually enhance the responsibility, creativity, technical level and positive work attitude of constructors. Strengthen the overall safety and quality management training level of construction personnel, improve the mutual supervision and management effect of the quality of civil engineering construction personnel, ensure close cooperation among construction personnel, technical personnel, management personnel, supervision personnel, etc., deal with possible management and control contradictions in the construction process in a timely manner, solve various construction legacy problems, build a reasonable communication and coordination management mode, and ensure a concerted planning management effect.

\subsubsection{Effective auxiliary control and management measures for raw materials}

It is necessary to strictly control the cost standard of civil engineering construction quality, and to strictly select, control and manage the quality, quantity, performance, planning level and other elements to ensure the safety of the construction quality of Shiyu project. It is necessary to analyze according to the contents responsible by relevant personnel, make clear the common specific work contents of raw materials and production, carefully manage and inspect, strictly control, improve the specified use process of products, and ensure the implementation value meaning of effective control management standards for raw materials.

\subsubsection{Reasonable control specifications for equipment products}

According to the actual use of equipment, the key points and points of civil engineering construction management are analyzed, strict control and management are carried out on the construction process, and the standards and detailed rules for equipment construction quality control are defined. During the construction process, it is necessary to carry out specific analysis on the design drawings and contents, determine the construction scheme that meets the construction standards, control the usage in the construction process and the material procurement before construction, reduce the waste of funds as much as possible, continuously improve various possible interruptions and deficiencies in the construction progress, ensure the effective collection of equipment quantity as much as possible, and continuously improve the reasonable control effect of equipment products. Good equipment management is directly related to the overall quality and safety level of construction equipment. If the price is too high or the material usage cost is too high, and the actual construction conditions exceed the inherent capital usage, waste will be caused, which will seriously affect the reasonable control of construction quality. It is necessary to analyze according to the standardization and control level of the actual civil engineering construction quality, to clarify the possible deficiencies and difficulties in the construction quality control, to analyze the standard 
forms and schemes of actual management control of equipment manufacturers, to select manufacturers with high sexual price, and to improve the reasonable control effect of equipment quality.

\subsubsection{Implementation plan of countermeasures to improve the control level of fund management}

In the process of construction management, civil engineering construction units need to reasonably collect and purchase raw materials, define the use standard of equipment, bid for land, analyze the use cost of employees and other links, gradually improve the use efficiency of funds according to the cost control process, avoid all kinds of negligence that may exist in the management process as much as possible, stop and deal with the possible waste of resources and funds, solve the adverse effects of various decisions in civil engineering construction management, and strengthen the construction management control level of civil engineering. Adopting reasonable quantitative compilation and quantitative cost control management methods to gradually improve the content of cost control management. Fully implement all aspects of civil engineering construction management, analyze the use of funds and the control of purchasing materials expenses, etc. to clarify the control amount and standard of actual enterprise construction funds, and gradually improve the overall economic development benefits of the enterprise. In addition, it is also necessary to strengthen the effective financial supervision, management and review process, gradually reduce all kinds of unreasonable economic expenses, reasonably reduce and control the overall cost level of construction management, and improve the economic efficiency level of capital operation. According to the demand, we will continuously improve the overall financial standard management level of civil engineering, try our best to avoid the phenomenon that the accounts and things do not conform to each other, accurately count the inaccurate phenomenon of capital and actual cost accounting, clarify the difference of actual profit data, analyze the system standard of actual accumulative economy, reasonably control the increase and decrease of cost, manage and control the phenomenon that the cost is unbalanced, and ensure the overall effective, sustainable, stable and rapid development of the enterprise.

\section{Conclusion}

To sum up, it is necessary to reasonably analyze the quality control process of civil engineering construction management according to the actual quality control standards, to determine the management level of relevant factors to carry out the efficient management mechanism of enterprises, to carry out efficient and perfect quality standard control for civil engineering construction units, and to ensure the core value standard process of the overall production process in civil engineering construction standard management. To improve the overall construction management level, enterprises need to reasonably control the management quality and management standards, define the key points and key points of civil engineering construction units, analyze and effectively improve the content of quality control management, carry out reasonable training and analysis on relevant personnel, ensure the management effectiveness of construction quality and safety, gradually improve the comprehensive management control level of personnel, improve the construction work efficiency of civil engineering units, improve the construction quality control of civil engineering construction, improve the safety, stability and effectiveness of civil engineering construction, improve the overall construction quality level of civil engineering, and ensure that civil engineering construction meets the actual overall construction development needs and functions.

\section{References}

1. Ran ML. Research on construction technology of mass concrete structure in civil engineering buildings $[\mathrm{J}]$. Building Materials and Decoration 2019; (36): 10-11.

2. Chen SS, Xie F. Analysis of construction technology of concrete structures in civil engineering buildings $[\mathrm{J}]$. Building Materials and Decoration 2019; (36): 28-29.

3. Wang XP, Xing KF, Deng L. Research on quality cultivation of outstanding engineers in civil engineering based on structural design competition [J]. Building Materials and Decoration 2019; (36): 193-194. 